\title{
Culture in the layers of contemporary discourses and historical archives: A review of Anna Maria Lorusso's Cultural Semiotics
}

\author{
Sara Lenninger
}

\begin{abstract}
In Anna Maria Lorusso's book Cultural semiotics: For a cultural perspective in semiotics (Lorusso, 2015) the reader is offered an initiated review of key representatives of $20^{\text {th }}$ century structuralism in semiotics and its entries into poststructuralism, with focus on method of analysis. Related to the theoretical discussions on semiotics and culture, Lorusso offers a series of case studies in semiotic analysis of cultural texts. In this review article, I discuss and evaluate the four strands in cultural semiotics suggested by Lorusso. Further, I draw implications for deciding on the themes and objects of studies in a semiotic realm that focuses on text.
\end{abstract}

Keywords: culture, structuralism, interpretation, regularisation, Greimas, Lotman, Eco, Foucault

\section{Revisiting structuralism}

Analogously to the way Saussure (1968 [1916], p.25, 33), in his time, invited "everyone" to study "the life of signs in the framework of social life", Lorusso (2015) now calls for semiotic studies to open up for interdisciplinary dialogs. Indeed, already from the first pages in Cultural Semiotics: For a cultural perspective in semiotics, Lorusso emphases that semiotics implies genuinely interdisciplinary research. Thus from the start she captures the reader's interest. Moreover, it does not become less stimulating when she makes it clear on that she will be revisiting some classical readings in semiotic theory. That is, Lorusso connects "the classics" in semiotic theory in general, and cultural semiotics specifically, to Levi-Strauss' anthropological and Saussure's linguistic structuralism. This, I think, is a valid characterization, although she separates (by name) only one out of four designated vocations discussed in the book as the structural vocation in cultural semiotics. Vocation is the term that Lorusso uses to describe and define four different analytical methods within four different branches in the domain of cultural semiotics. Her choice of terminology enhances the analyses as a kind of pursuit, but also emphases semiotics as an activity - the doing involved.

Although not specifically formulating this as explicit criticism, Lorusso questions a semiotics that settles with an aim to identify only the parts of a system. A semiotic approach, she argues, is not to detect clean or simple elements of meaning and meaningmaking but to find the semiotic systems "which as such has features of both form and content" (Lorusso, 2015, p.10). More precisely, the pivotal point in semiotics according to Lorusso is to investigate and to interpret the correlations between expressive elements and contents. A substantial complication, Lorusso claims, is then to define and to delimit a corpus in a cultural semiotic investigation. However, when the author by the end of the book presents her own view on what it takes to endorse the scope of a cultural semiotic analysis, most of the issues remain.

Lorusso's aim is neither restricted to merely review what has already been said in semiotic structuralism, nor is it to present a new semiotic theory of culture. Rather, her ambitions are bold in an alternative sense, since she aims to "restore this branch of thinking to its authentic forms in terms of both critical and social content" (Lorusso, 
2015 , p.2). In order to carry out this revision Lorusso suggests a comparative reading of different versions of structural approaches in anthropology and linguistics. The cultural perspective on text along the lines of Juri Lotman and the Tartu school is central. Moreover, from within a structural approach she also argues that it is necessary to learn from C. S. Peirce's investigations into meaning-making processes. Indeed, by the end of the book the role of habit is proposed to be the main unifier across the varieties of present and past utterances, meanings, and discourses.

The linking of these schools and scholars in semiotics is not unique and Lorusso also emphasizes the work of Irene Portis-Winner since the 1970-ties (e.g., see PortisWinner, 2013) The originality of Lorusso, however, is in the way these different voices come into a polyphonic dialogue, side by side, rather than being merged in an effort of synthesis. Moreover, in connection to three of the four vocations informative case studies are presented. The aim with these case studies is twofold: both to practice the methods of investigation associated with the discussed vocation, and to support the argument that no single method is enough to cover such a complex phenomenon as culture. Different methods are shown to be appropriate for different analytical "excisions" of culture. In the end, however, when on the proposal for a synthesizing vocation is discussed, the project has grown and no illustrating case study is presented.

In short, four different vocations representing four different methods in cultural semiotics are suggested by Lorusso: (a) the structural vocation, (b) the systemic and translational vocation, (c) the encyclopedic vocation and finally (d) the archaeological and normative vocation. The three presented case studies aim to exemplify the claims and interests of $(\mathrm{a}-\mathrm{c})$. Each case study could be extensively discussed but due to space limitations, I will concentrate on the theoretical claims. Still, to give a few examples, in the first case study (illustrating the structural vocation) the corpus consists of 50 photographs collected from websites from different organizations that work in humanitarian affairs. The aim of the analysis is to trace "an aesthetics of pain" that is claimed to be manifested in the pictures. The second object of analysis (following the systemic and translational vocation) is from the communicative activities of a protest organization, the Madres, also known as Mothers of plaza Mayo. The analysis investigates the group's use of different forms of expression such as physical actions (e.g., marches), linguistic expressions and visual markers (e.g., the white scarf) to communicate their on-going protest concerning missing children from the time of dictatorship in Argentina. The third case study concentrates on the encyclopedic vocation and pays attention to the use of the Guy Fawkes-mask as an emblem for Anonymous and the Internet culture protesting against the power of authority. In general, it is worth noting that Lorusso choses themes that are all devoted to ethical and social concerns.

In discussing the concept of culture Lorusso offers a critical reading of key concepts in structural theories, such as text and code. Thus these concepts will also be in focus here. The concept of sign, however, is only briefly commented - as if it were an uncontroversial concept, which is hardly the case. Nevertheless, what is said about the sign is noteworthy. Lorusso (p.30, 2015) points out that "all sign phenomena are both social and systematic" as they are connected to communication and human understanding. Moreover she points to the relevance of learning from both Saussure's and Peirce's theories on meaning relations. Basically, signs, following Saussure's conception, have by their nature differential value, and work on differences, oppositions, 
and contrasts. By also following Peirce, however, signs are also described as processes based on regulative rather than oppositional structures.

Moreover, the perspective is historical. The cultural semiotic analysis is presented as a work of restructuring: the overall aim of a semiotic analysis is to reconstruct the processes which have generated a text. As a consequence, the concept of text is central. On the one hand, Greimas' call for reinvestigating meaning processes (e.g., Greimas, 1987) is clearly noticeable from the start to the end of the book. In leaning more closely to the Tartu school's concept of text, however, Lorusso avoids Greimas' problematic project of tracing back meaning to some simple sets of core elements.

Lorusso agrees with Foucault (1975) that since everything can be studied as a cultural phenomenon, a major challenge in the study of culture is to establish and delimit a corpus. To make this task less unwieldy, Lorusso presents her view on some characteristics to understand culture and how to study it. Culture can be seen as collective memory that is based on shared experiences and structures, originating from the past but acting in the present and the future. Moreover culture is a creative and selective space. At the same time, it is regulative. In culture there is a process of regularization keeping it together by on-going formations of norms and rules. Again, the structural approach pervades the description. A text or a corpus cannot be understood as an isolated phenomenon but must be defined by its relation to something else.

\section{Mirroring the paths of structuralism in cultural semiotics}

In this section I wish to discuss Lorusso's proposal of four analysis methods in cultural semiotics in its close connection to some influential scholars in semiotics. Notably they are all related to different branches within semiotic theory that have a common ground: an interest in the utterance or the text, more than on experience and subjectivity.

\subsection{Organization of a text: the structural vocation}

The first chapter deals with the structural vocation in cultural semiotics. Following Greimas (1987) Lorusso emphasises the structuralist perspective as a kind of method. Moreover, she sees this predominantly as a method to articulate and sort out levels of meaning in texts and thus to bind a text together. Nevertheless, some serious pitfalls connected with the structuralist perspective are identified. Lorusso warns both for the risk of having too broad a claim (e.g., the call to examine all cases of a cultural phenomenon), and to be too lose in defining the conditions for the analysis (e.g., the organization of layers or associated contexts). The first warning concerns the problem of constructing the corpus and is addressed to the work of Levi-Strauss. The second concerns losing the aim of a well-organised analysis of a texts' overall signification ending up in "a free raid on the text" (Lorusso, 2015, p.51). Although criticized for different reasons, the latter warning targets Derrida's work on deconstruction (e.g., Derrida, 1967) and Barthes' outcomes of textualism (e.g., Barthes, 1977, 1985). Lorusso's critique of Barthes is discussed in general terms, but more specifically, the lack of a theory of culture and an increasing distance from Hjelmslev's (1954) theory of intersections (semiotic stratification) in language are pointed out.

In a rigorous structural vocation, the analysis of text, and the manifestation of text, is clearly organised in layers of meaning. The organisation is expected to correspond to 
the structure of relationships working on all levels of the text. Notably, critical properties of the text are exposed here. Within the structural vocation, a text is a multi-layered semiotic phenomenon and thus cannot be limited to perceived empirical objects; as such, it is a general and abstract model pervading human culture. Following the structuralist perspective, any analysis of a text (be it manifested as a picture or a verbal narrative) has to be level-based, while no single level of text exhausts its potentialities of meaning. Thus, the job for the analyst is to be clear on what is the theme of investigation and then, accordingly, to be transparent on the choices and selections made in order to trace the organization of meanings.

\subsection{Translation of texts: the systemic and translational vocation}

Similarly to the structural vocation, the systemic and translational vocation also works with a textual corpus. However, while the structural vocation is concerned with recreating and identifying layers of meaning that are already predetermined in its organization, the systemic and translational vocation, represented by Juri Lotman and the Tartu school, is dynamic and stresses variation, change, filtering and development of meaning.

According to Lotman (2009) culture is a public sphere derived from the circulations and changes of the texts that constitute it. The aim of the systemic and translational vocation, as outlined by Lorusso, is to distinguish and analyse the constitution of new texts in the flow and noise of on-going communication. Moreover, the systemic and translational vocation works with clashes of meaning in the public sphere; the relevant relations are to other texts, not the layers within a text. Thus culture is a place for more or less unforeseen and dynamic meetings of different texts, thus giving rise to new texts. Pluralism is necessary to keep a culture alive, and any meaning emerges from gaps - not the overlaps - of meanings in communication. But how then, is anything understood? Lorusso (2015, p.70-71) explains Lotman's position: "The fact that culture consists of several languages and that all of these languages are, at a certain level, similar is something that is at the same time both unitary and plural".

Thus, in distinction to Greimas' text-as-a-model theory (in which layers and structural elements of texts form a model for understanding culture), Lotman's aim is not to trace or identify the unifying structure or any specific level in the texts. Rather, according to Lotman (2009), the living nature of culture exists through the dynamic life of texts. The rhythm - or speed of change - in and between levels of meaning in a given culture varies across its processes. Meaning is seen as pragmatic and related to variations by means of expression, such as between the use of gestures, spoken and written language. These variations in time scales and in forms of utterances are recognized as vital forces for retranslation and the development of meaning in culture. Culture is not only pluralistic, it is also asymmetric. Indeed asymmetry is described as the organizational law in the systemic and translational vocation (Lorusso, 2015, p. 96). That is, the meeting of other texts in culture is not unbiased. Moreover, the inherent asymmetric relations in translation processes cause tensions in culture - tensions that also force the construction of new texts and thus create changes in culture. 


\subsection{Interpretation of culture: the encyclopedic vocation}

Scales are in focus again when Lorusso presents the encyclopedic vocation, represented by the work of Umberto Eco (e.g., 1976, 1984). Here locally regulated rules are analysed as core factors for regulating meaning in any utterance. Thus rather than following the same general and immanent structures pervading all levels of meanings according to the Greimasian school (and the structuralist vocation) one now must find the local instructions for organizing meaning in any specific utterance. Moreover, and in distinction to the dynamics in the systemic and translational vocation, the semiotic processes are now understood as taking the role of negotiations. Instead of forcing new texts into the already rich flora of texts in a culture, as done by Lotman (2009), the interpretative processes analysed according to the encyclopedic vocation stress culture as a place for negotiations between texts. Thus, rather than focusing on differences and boundaries which force translations, the interpretation process leads to smoothing out differences in meaning. At the same time, this smoothing-out process leading to the ability for an utterance to blend-in can also be used as cuckoo eggs in an aggressive strategy, as shown in Lorusso's case study on the Anonymous.

Different cultural versions of reality are formed as discursive proposals (Eco, 1999). The interpretation of these proposals, or cultural units, is understood as a unifying process and not primarily as a polemic situation demanding the creation of new texts. This is also why culture tends to bond with ideology. According to Lotman and the Tartu school, we can expect that this kind of bonding either leads to "silence" (by inclusion or exclusion of other texts) and thus perhaps "the end of a culture", or it must collide with another text that is strong enough to challenge the first one. According to Eco, on the other hand, the negotiations in culture fall back on local, contextual, interpretation of codes.

As noted in the introduction of this article, reviewing the concept of code is also a subtheme in Lorusso's investigation of structuralism in cultural semiotics. The crucial point in the description of the notion of code here is the claim that it must not be interpreted as a one-to-one information key and cannot rest with the description of being traced via bi-polar categories, as in Levi-Strauss' (1979) oppositional pairs or Greimas' (1987) semes. Rather the code is to be understood as an instruction, bringing in rules of interpretation. However, as noted above, the rules themselves are also subjects for interpretation and thus are constantly negotiated in local networks. The crucial point here is that even if codes work across different texts in a given culture, they also undergo processes of change. The aim of the interpretational vocation concentrates on contextualisation and placing a statement (the utterance) in its relevant social networks. Embedded meaning is not understood as layers of meaning stemming from immanent structural meaning systems (as in the structural vocation) but as shaped through a history of negotiating meaning. The study of semiotic processes is now the study of culture and cultural processes.

\subsection{The making of regularities: the archaeological and normative vocation}

Finally, with the archaeological and normative vocation, Lorusso returns to the difficulty of the concept of text. Learning from Lotman's and Eco's lessons, Lorusso 
stresses that meaning comes in many versions. Messages are transformed, meanings are translated, and cultures act on different instructions or codes. In the archaeological and normative vocation, process is once again stressed and especially processes of regularisation. But any process of meaning making must also deal with chance. On-going processes of regularisation and selection are pointed out as the central matter for culture, and for any cultural semiotic analysis. Thus, in the archaeological and normative vocation, it is neither texts nor the codes (i.e., instructions from the processes of regularizations) per se that constitute cultural meaning. Rather, these elements are only stages in culture - stages that slow down the processes. Texts and codes are the manifestations and practises that function as the moments of regularisation and stabilisation in culture, "the moment where culture builds its references, its canon, its norms" (Lorusso, 2015, p.192).

A local and provisional logic, however, does not exclude the relevance of immanent structures affecting a bigger whole, Lorusso emphasises. Any meaning or knowledge (episteme) is understood as a system of relationships and its constructing conditions. Thus the task in the archaeological vocation is to bring those underlying structures of communicated meanings to the surface and unfold relevant constructing conditions. Notably, this was also the overall project in structuralism. Now, however, the instruments for analysis have grown and become more sensitive to trace and describe culture as a multifaceted human project. Understanding diversity and pluralism are per se key factors in analysis.

\subsection{When contemporary discourses and historical archives meet}

In the encyclopedic, or interpretative, vocation all practise of meaning is studied as culturally located, although the many versions of practice also allow for relationships between cultural forms. If the instructions (i.e., the code) to understand an utterance (i.e., a practice of meaning making) follow from the rules in a local network, then a central work of the encyclopedic vocation must concentrate on placing its object of investigation in a relevant social network. In Lorusso's case study illustrating this vocation, it becomes clear that the analysis is not primarily about identifying the overall context of a single utterance but about tracing the negotiations in a communicative strategy. By lending codes from a different context, and thus negotiating meaning in a given utterance, a first message can impose on a second meaning. In this way meaning, and meaning structures spread into new cultural arenas.

Contemporary discourses and historical archives meet in the utterance as is the case with the Guy Fawkes mask. The Guy Fawkes mask which is well known from the film $V$ for vendetta (directed by James McTeigue, 2005) was designed from a graphical novel by Allan Moore in the 1980-ties originating from the novel Guy Fawkes, or the Gunpowder Treasure by William Harrison Ainsworth (1840) about the accusations on Guy Fawkes' (1570-1606) participation in a conspiracy against the English parliament in 1605. Hence, by strategically selected loans of cultural ready-mades and real life narratives, new messages reactivate already passed down codes as "palimpsests" of former meaning practices. This practice, regarded as an interpretative process, involving an actual and situated context and fragments from already evaluated meanings is at the heart of Lorusso's view on what culture is and how to understand cultural semiotics. 
Lorusso, agreeing with Greimas, maintains that there is a synthesising logic that transgresses and extends individual practises of meaning making. The synthesising logic, however, is not a specific structural pattern; it is a process. Essentially, she suggests, that this is the process of regulation. More specifically, it is the regulation of interpretation. Lorusso now turns to Peirce and the concept of habit, as a pragmatic consequence in the process of stabilizing interpretations. So, the object of investigation in the semiotic analysis is the practice of meaning making that is under the process of normalizing. This is an interesting turn. However, the universalism in Peirce's philosophy also comes with the package. I will come back to this in the next section but for the sake of balance, I must first comment on the methodological discussions in the presentation of the archaeological and normative vocation. Remarkably, the presentation of the archaeological and normative vocation is not followed up with a case study. This lack is possibly a result of this vocation being in an early phase of its stabilization process. More critical thought is devoted to what is discussed by Lorusso in the fourth vocation, namely once again the problem of forming a corpus.

In short, the review of the last vocation ends up with a sum up of insights from previous lessons. Hence it can be noted that a semiotic analysis targets cultural objects. These are discursive, thus historical, social, contextual objects in change. Moreover, there are layers of meaning in culture but, unlike in the Greimasian school, concrete utterances do not manifest the rudiments of the overall structure of meaning relations. That is, processes of regulation pervade the discourse as a whole, but the processes of its parts may vary from the process as a whole.

The vision in the archaeological and normative vocation is far-reaching. It is expected to be a semiotic approach that allows us to think in terms of regularity throughout time and space. As a consequence the object of investigation is discourse, not primarily texts, but again it has become quite rich, and in need of more detailed investigation.

\section{Subjects and meanings}

As pointed out, Lorusso's revisit to the structural route in cultural semiotics concludes with a suggestion for an approach that also holds on to central ideas in structuralism, such as the view that meaning is layered and relational. At the same time, what is actually given in perception is not in the focus of the investigations, nor are the perceivers. This remark leads to two themes that will end the present discussion. The first theme relates to the concept of text and is connected to discussions on the object (i.e., the text) and the subject (i.e., the area or theme) of investigation. The other theme concerns the approach to meaning (making) as a process and opens up questions concerning the interpreters. Lorusso's discussions deal with the first theme but the second one is left out.

Hand in hand with the suggested changes in the concept of text, the subject of investigation is also changed. In short three main text-related concepts are presented: (a) the text as a model, (b) the text as mechanism and (c) the text as a function in discourse. The text as a model is the idea of the text as a general abstract pattern pervading all levels of meaning, and has as a consequence that the text (model) is also manifested in concrete utterances. The objects of study can therefor be concrete utterances by which 
the meaning relations (the subject/object of study) are made communicable on the level of manifestation.

The specified subject in the case study illustrating the structural vocation was earlier described as "the aesthetics of pain". Thus the possibility of such a subject of investigation is crucial for the analysis in the first place. However, there is no model presented for formulating this as a theme (the subject of study) - and perhaps more seriously - there is no model for rejecting it. Nevertheless, the theme is given and Lorusso also suggests an analytical grid that aims to keep the analysis consistent across the corpus of 50 selected photographs. Lorusso is clear on the point that there will be reasons for deciding on the choices of these grids and themes and that therefore these have to be clearly presented. It is unfortunate, however, that Lorusso is unclear with concepts for pictorial meaning making when the analyses are derived from features that can be seen in the picture (such as bodily postures, arrangements between different bodies and objects on the picture surface, facial expressions, but also possibly actions like "showing" or "sleeping") and especially when the interpretation is kind of narrative (someone is "looking as if expecting something from someone", or the "gaze calls out to us"). Such interpretations are all reasonable, at least if we accept that the perceiver's interpretation is related to former experiences of the visual and lived world as well as from other texts (what is already said in the perceiver's culture). But the analyses become ambiguous when the different conditions for meaning (based on what can actually be seen in the picture and what can be, or is, inferred within more contextual experiences of narratives) are not pointed out.

Lorusso's analysis follows from a Greimasian view where the picture display is the (textual) manifestation of a grander narrative that also is embedded in the text (Greimas and Courtés, 1979). Therefore, the analyses in the structural vocation focus on sublevels of the text and not primarily on the interpretational process in the perceiver or on the interaction between the picture and the perceiver. This is perhaps also why the narrative dimension of meaning in pictures is not distinguished from the figurative dimension when Lorusso presents the "visual dimension" in a short passage. By still following Greimas, the visual dimension is divided in two types of "language": figurative language and plastic language (Lorusso 2015, p.62, cf. Floch 1985). The figurative language, which is a type of visual meaning reflected by portraying "figures of the world" (Lorusso 2015 , p.62), is discussed in terms of "the woman-Madonna with child". Thus, the figurative meaning of pictures is not clearly separated from the narrative dimension.

The point here is not to deny the impact of "visual histories" (Lorusso 2015, p.57) or of narrativity (i.e., the force prior to narratives according to Greimas). Rather it is a call for a clearer understanding of narratives and the figurative meanings in the interpretation of pictures. Moreover, the potential of the plastic domain (i.e., meaning making dealing with lines, colours, textures, shapes etc.) is hardly met at all. A longer discussion would be needed here but it suffices to point out that Lorusso does indeed bring up three important domains for analysing meaning making with pictures - the domain of narrative, the figurative and the plastic domains - but overlooks the potentials of being clear on them and their mutual relationships in pictorial making meaning.

The alternative views on the concept of text in the other vocations do not focus on text as patterns but rather texts as "places" or "forces" for processes. In Lorusso's presentation, this involves either focus on the text as a mechanism or on the text as a 
Public Journal of Semiotics 8 (1)

function. In the systemic and translational vocation, the text is the place where meanings evolve and come at play, based on the hierarchical and asymmetric relations in communicative cultures. In this vocation, meaning is always a translation process. It is the processes in texts, and between texts, that produce and constitute culture. Tracing the processes behind changes in the text must be central here. It is noteworthy that the mechanisms must be greater than the messages in this vocation. It is not what is said that matters for the development or change of culture, but rather what texts do to other texts that is in focus. Such as when dominant texts in culture absorb or translate features from less dominant texts into their own features.

In the archaeological and normative vocation, the object of investigation (i.e. the corpus of a culture) cannot be derived from texts or their contextual mechanisms only. The text is primarily discursive in nature. Nevertheless, the text is only one subject among other subjects of investigation in the greater "archive" including habits, analytic tools, codes and things we do not yet know. Thus in the archive we must also find the vocations discussed by Lorusso themselves! Hence in the final discussion of vocations the author concludes that it is from the discourse, not primarily from texts, that we learn about and can study culture.

A further issue connected to the dilemma of unity or pluralism is the question of the interpreting subject. Lorusso $(2015$, p.13) shortly spells out a human(ist) perspective by assuming that culture is something that "emerges from the minds of people". In general, however, Lorusso avoids the notion of mind(s): meaning is constituted as relationships in and between patterns, mechanisms of contexts, in the force of discourse, and passed on from the encyclopedic knot of cultural memories, along the lines of Eco (1976, 1984). Notably, in discussing Lotman's theory on cultural encounters, Lorusso describes the asymmetric relations in terms of a mechanistic law. Someone like Sonesson (2000), on the other hand, takes more focus on the Ego vs. Alter perspective also present in Lotman's writings and in the Tartu school. The asymmetric relations are then due to the idea that cultural encounters are biased from the point of view of one's own culture. Hence Sonesson includes the point of view of the interpreting subject in the analysis.

Arguably, Greimas and Courtés (1979) were wrong in reducing human thinking to systems of oppositions and contradictions. However, the fact that they grounded their theory on human thought is nevertheless noteworthy. Lorusso, on the other hand, follows interpretations of Peirce where human thought is understood as a part of a larger, universal, system of meaning relations. It is, in the end, a universe of relationships that is embodied in human culture by way of habit. It is a system that is so large and abstract that possible specificities in the construction of human meaning-making are not necessarily felt as relevant. Possibly, this could be a matter of perspectives or scales. Still, at least to some degree, the perspectives of the interpreting subjects (human beings) need to be included in the great archive of meaning.

\section{Concluding words}

Many interesting discussions in the book have been left out due to constraints of space and time. In these days when structuralism is no longer as dominant in semiotic theory as it was before, Lorruso's work is both rich and brave. By reintroducing the classics of the 
structuralist branch of semiotics, Lorusso exercises her views on culture and cultural processes in three case studies. By bringing different strands in structural theories of meaning and culture into a comparative approach she ends up with a situation where different scales in the study of culture need different scales in the claims of the analytic tools. A micro study (following a local rule) does not have to follow the model of a macro study (taking the grand perspective in the notion of text), since the relevant relations in the micro study may not have the same predispositions as the relevant relations in a macro study. And what makes the significant changes in the larger scales may not be traced from its details. Lorusso's answer to the dilemma of unity or pluralism is that this can be resolved by altering the scales of the studies and framing them as instances of meaning making that can be traced as processes of regularisation within the archive of human culture.

\section{References}

Barthes, R. (1977). Image, music, text. London: Fontana

Barthes, R. (1985). Láventure sémiologique. Paris: Seuil

Derrida, J. (1967). De la grammatologie. Paris: Minuit

Eco, U. (1976). A theory of semiotics. Bloomington: Indiana U.P.

Eco, U. (1984). Eco, Umberto (1984). Semiotics and the philosophy of language. Bloomington: Indiana U.P.

Eco, U. (1999). Kant and the platypus: essays on language and cognition. London: Secker \& Warburg.

Floch, J-M. (1985). Petites mythologies de l'œil et de l'esprit: Pur une sémiotique plastique. Paris: Éditions Hadès-Benjamins.

Greimas, A., J. (1987). On meaning: Selected writings in semiotic theory. Minneapolis: University of Minnesota Press.

Greimas, A., J., \& Courtés, J. (1979). Sémiotique dictionnaire raisonné de la théorie du langage. Paris: Hachette Université.

Hjelmslev, L. (1954). La stratification du langage. WORD, 10:2-3, 163-188, DOI: 10.1080/00437956.1954.11659521

Foucault, M. (1975). Entretien sur la prison: le livre et sa method. Magazine littéraire, 101, 27-33. http://1libertaire.free.fr/MFoucault193.html [20171207]

Lévi-Strauss, C. (1979). La voie des masques: édition revue, augmentée, et rallongée de Trois excursions. Paris: Plon.

Lorusso, A., M. (2015). Cultural semiotics: For a cultural perspective in semiotics. London: Palgrave Macmillan.

Lotman, J. (2009). Culture and explosion. Berlin: Mouton de Gruyter

Portis-Winner, I. (2013). Semiotics of culture and beyond. New York: Peter Lang

de Saussure, F. (1968 [1916]). Cours de linguistique generale. Paris:Payot.

Sonesson, G. (2000). Ego meets Alter: the meaning of otherness in cultural semiotics. Semiotica, 128-3/4, 537-559. 
Public Journal of Semiotics 8 (1)

\section{About the author}

Sara Lenninger wrote her doctoral thesis, and has conducted subsequent research, on semiotics with focus on visual and pictorial meanings and semiotic development. She works as lecturer at Kristianstad University and is affiliated with the Centre of Cognitive Semiotics at Lund University, Sweden.

Educational Sciences

Kristianstad University, Sweden

Sara.Lenninger@hkr.se 